http://jmscr.igmpublication.org/home/ ISSN (e)-2347-176x ISSN (p) 2455-0450

crossref DOI: https://dx.doi.org/10.18535/jmscr/v8i9.12

\title{
Role of Arthroscopy in Osteoarthritis of Knee Joint
}

\author{
Authors \\ Dr Md. Azfar Nawaz ${ }^{1}$, Dr Ajay Kumar Mahto ${ }^{2}$ \\ ${ }^{1}$ Junior Resident, Department of Orthopaedic, KMC, Katihar \\ ${ }^{2}$ Professor and Head, Department of Orthopaedic, KMC, Katihar
}

\begin{abstract}
Introduction: Degenerative arthritis is the most frequent disorder in elderly patients. Knee osteoarthritis more likely to result in disability than OA of any other joint. The symptoms of OA of the knee are due to the effects of loose fragments of the articular cartilage, debris, denuding of subchondral bone, degenerative tears of menisci, loose bodies, osteophytes, synovitis, joint effusion and limited motion caused by contractors, pain and malalignment. There are many treatment options available for the management of $O A$ of the knee joint. Analgesics, physical and occupational therapy, arthroscopic joint debridement, joint lavage and joint replacement have all been advocated as management techniques.

Method: The study was prospective, conducted in the department of orthopaedic, Katihar Medical College \& Hospital, Katihar. 50 Cases included in this study are the patients attending outdoor department of Katihar Medical College \& Hospital having Inclusion Criteria, patients with mild and moderate osteoarthritis, skin condition of the operative field normal, patients with little relief with analgesic and physical therapy, patients and party agreeing to have arthroscopy (after counselling) and exlusion criteria, patients unfit for undergoing operation during pre-anaesthetic check up, patients on irregular treatment of hypertension, coronary heart disease and diabetes mellitus etc. The duration of the study was 1 years.

Result: According to this study the mean age was 48 years and most commonly seen in overweight and obese female than male presenting with pain (100\%), swelling (70\%) and restricted joint mobility (90\%). Narrowing of joint space on $x$-ray is mostly seen in grade 4 (Kellegren-Lawrence radiological grading) followed by grade 3 and grade 2. Post operatively improvement in pain severity score is most commonly seen in grade- $2(61.11 \%)$ followed by grade $-3(31.81 \%)$.

Conclusion: The role of arthroscopic debridement does not shows any improvement in the ongoing pathological process; it is only provides symptomatic improvement in patients of low grade osteoarthritis where it provides pain relief. Conversely, in patient with sever osteoarthritis there is very limited role of arthroscopy.
\end{abstract}

\section{Introduction}

Degenerative arthritis is the most frequent disorder in elderly patients. Knee osteoarthritis more likely to result in disability than OA of any other joint. The symptoms of OA of the knee are due to the effects of loose fragments of the articular cartilage, debris, denuding of subchondral bone, degenerative tears of menisci, loose bodies, osteophytes, synovitis, joint effusion and limited motion caused by contractors, pain and malalignment. 
There are many treatment options available for the management of OA of the knee joint. Analgesics, physical and occupational therapy, arthroscopic joint debridement, joint lavage and joint replacement have all been advocated as management techniques.

Arthroscopy has been used for the management of patients with OA with varying degree, the varieties of techniques and the different methods of assessment that have been used to make a comparison of studies difficult. In order to avoid unnecessary failure rate from an indiscriminate use of arthroscopy in an OA patient. The orthopaedic surgeon must attempt to identify accurately those subsets of patients who may benefit from such surgical procedure.

Knee arthroscopy has historically been a common treatment for knee osteoarthritis. Knee osteoarthritis is a common condition affecting more than $10 \%$ of the population over 60 years old. Knee arthroscopy has been a common tool in the treatment of knee OA. However a well publicised study of Mosley et all combined with a Cochrane review of literature up to 2006 indicates that arthroscopy should not be used in knee arthritis.

\section{Aims and Objectives}

The aim of this study is therefore to perform a systematic review of literature on the use and effectiveness of arthroscopy in treating knee osteoarthritis with or without meniscal degeneration.

\section{Material and Method}

The study was prospective, conducted in the department of orthopaedic, Katihar Medical College \& Hospital, Katihar. 50 Cases included in this study are the patients attending outdoor department of Katihar Medical College \& Hospital having Inclusion Criteria, patients with mild and moderate osteoarthritis, skin condition of the operative field normal, patients with little relief with analgesic and physical therapy, patients and party agreeing to have arthroscopy (after counselling) and exlusion criteria, patients unfit for undergoing operation during pre-anaesthetic check up, patients on irregular treatment of hypertension, coronary heart disease and diabetes mellitus etc. The duration of the study was 1 years.

\section{Methods}

A sequence of methods to be used during this study are as follows:

1. Selection of cases- Based on medical history (Name, age, sex, history of trauma, history of any pathology etc.)

2. Examination of Knee- To examine the attitude, disability, deformity, muscle wasting.

3. Relevant laboratory investigationComplete blood count, haemoglobin estimation, Fasting \& Post Prandial Blood Sugar, Blood Urea, Serum Creatinine, Bleeding \& Clotting Time.

4. Radiological Study- Plain X-Ray of knee view AP and Lateral view.

5. MRI (in selected cases)

All the patients selected will then be operated and followed up to 2 weeks, 6 weeks and 6 months with clinical and radiological assessment at each visit. In all cases preoperative and post operative charts will be maintained with regular assessment for proper post operative recovery assessment.

\section{Kellgren Lawrence Grading of Osteoarthritis ${ }^{1}$}

Grade 0: no radiographic features of $\mathrm{OA}$ are present

Grade 1: doubtful narrowing of joint space and possible osteophytic Lipping

Grade 2: definite osteophytes, definite narrowing of joint space

Grade 3: moderate multiple osteophytes, definite narrowing of joints space, some sclerosis and possible deformity of bone contour

Grade 4: large osteophytes, marked narrowing of joint space, severe sclerosis and definite deformity of bone contour. 
Method of Arthroscopic Examination and Debridement

After patients were considered for arthroscopy, and passing from pre-anesthetic checkup, patient was taken in Operation Theater, and after giving an appropriate anesthesia, patient was taken on operation table in supine position with both legs hanging down the operation table. A padded lateral post was used for stressing the knee to open up various compartments, necessary for diagnostic and operative procedure. The use of a padded lateral post attached to the edge of the operating table can be effective for valgus stressing in or near full extension, but it does not control rotation. A tourniquet was placed around the thigh, but was not inflated unless troublesome bleeding occurs. Inflation of the tourniquet blanches the synovium and other vascularized tissue and makes diagnostic evaluation of these structures more difficult. Meniscal vascularity and healing potential were evaluated with the tourniquet deflated and the intraarticular hydrostatic pressure low.

The tourniquet usually was inflated after exsanguinations of the limb. Tourniquet time was minimized and not exceeds 90 minutes for routine procedures to prevent possible deep vein thrombosis. Painting and draping of limb done under all aseptic precaution. All standard and optional portals were marked. Typically, the outlines of the patella and patellar tendon were drawn, medial and lateral joint lines were palpated with the fingertip and drawn, and the posterior contours of the medial and lateral femoral condyles were marked. But most of the time anterolateral and anteromedial portal was used. Anterolateral portal is located approximately $1 \mathrm{~cm}$ above the lateral joint line and approximately 1 $\mathrm{cm}$ lateral to the margin of the patellar tendon. Palpation of the inferior pole of the patella helps to ensure that the anterior portals are not placed too high; the portal should be approximately $1 \mathrm{~cm}$ inferior to the patella. Anteromedial portal is located similarly to the anterolateral portal: $1 \mathrm{~cm}$ above the medial joint line, $1 \mathrm{~cm}$ inferior to the tip of the patella, and $1 \mathrm{~cm}$ medial to the edge of the patellar tendon. Then scope canula with trochar was inserted in to the joint through the anterolateral portal and joint was distended with normal saline through. After sufficient distention of joint, trochar was removed and scope with TV camera was inserted in to the joint. Then knee was examined in the following order of compartments.

1. Suprapatellar pouch and patellofemoral joint

2. Medial gutter

3. Medial compartment

4. Intercondylar notch

5. Posteromedial compartment

6. Lateral compartment

7. Lateral gutter and posterolateral compartment

In present study, debridement included thorough normal saline wash, removal of loose bodies, removal of loose flaps of articular cartilages and removal of frayed meniscal margins and articular cartilages. Intra operative grading of articular cartilage degeneration was done by method described by Noyes - Stabler. ${ }^{2}$

Post- operative protocol

Patient allowed walking fully weight bare from next day only. And discharged on day two of post - op after dressing. Jone's dressing was removed in third post-operative day. Patient called for suture remove in OPD on 11th post-operative day and suture was removed. Patients were advised knee quadriceps and hamstring exercises. Patient called for follow - up on 6 weeks, 3 months, 6 months, and 1 year of post-operative day in OPD, and pain severity score was measured according to knee society pain score5 routine physical examination of knee was done for other physical signs. 
Table 1: Noyes - Stabler articular cartilage degeneration grading. ${ }^{2}$

\begin{tabular}{|l|l|}
\hline Grade of Articular Cartilage & Defect Description \\
\hline 0 & Normal articular cartilage \\
\hline IA & $\begin{array}{l}\text { Mild softening or discoloration of } \\
\text { articular cartilage }\end{array}$ \\
\hline IB & $\begin{array}{l}\text { Severe softening or discoloration } \\
\text { of articular cartilage }\end{array}$ \\
\hline IIA & $\begin{array}{l}\text { Partial-thickness defect of }<50 \% \text { of the total thickness of } \\
\text { articular } \\
\text { Cartilage }\end{array}$ \\
\hline IIB & $\begin{array}{l}\text { Partial-thickness defect of }>50 \% \text { of the total thickness of } \\
\text { articular } \\
\text { Cartilage }\end{array}$ \\
\hline IIIA & $\begin{array}{l}\text { Full-thickness articular cartilage } \\
\text { defect with normal subchondral bone }\end{array}$ \\
\hline IIIB & $\begin{array}{l}\text { Full-thickness articular cartilage defect with erosion of } \\
\text { subchondral bone }\end{array}$ \\
\hline
\end{tabular}

\section{Results and Analysis}

\section{1) Age Distribution}

The mean age in our study was 48 years. The youngest patient was 31 yrs and the oldest patient was 70 years old.

Table No 2: Age distribution

\begin{tabular}{|l|c|c|}
\hline Age in years & Number & Percentage(\%) \\
\hline $31-40$ & 17 & 34 \\
\hline $41-50$ & 14 & 28 \\
\hline $51-60$ & 13 & 26 \\
\hline $61-70$ & 06 & 12 \\
\hline Total & 50 & 100 \\
\hline
\end{tabular}

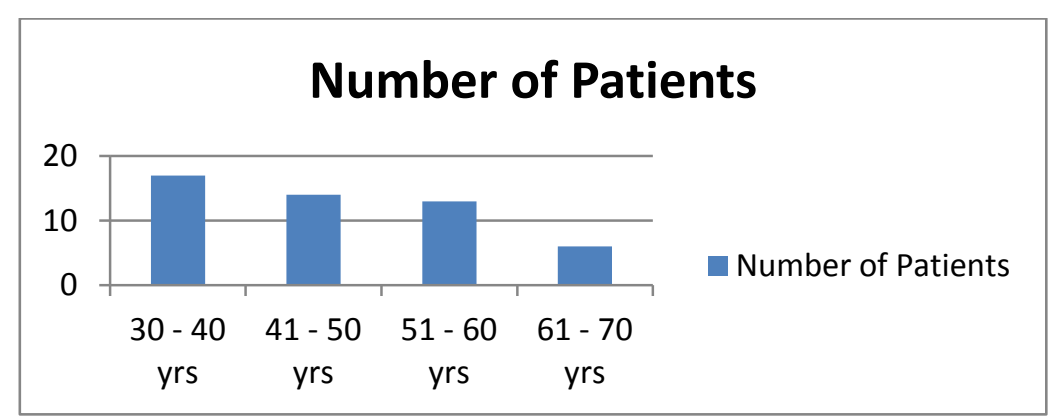

Chart 1: age distribution

\section{2) Sex Distribution}

Table No 3: sex distribution

\begin{tabular}{|l|c|c|}
\hline & FREQUENCY & PERCENTAGE \\
\hline MALE & 20 & $40 \%$ \\
\hline FEMALE & 30 & $60 \%$ \\
\hline TOTAL & 50 & $100 \%$ \\
\hline
\end{tabular}




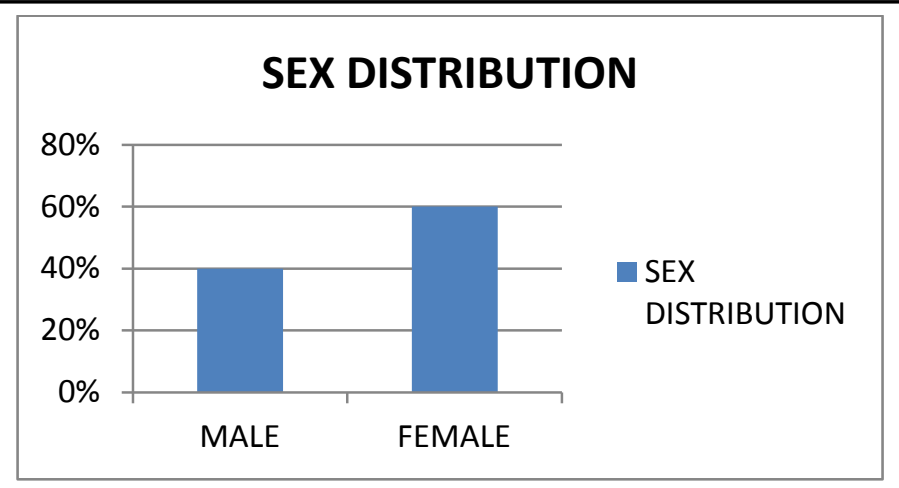

Chart 2: shows sex distribution

3) Side of Knee Involve

Table No 4: Side of Injury

\begin{tabular}{|l|c|c|}
\hline & FREQUENCY & PERCENT \\
\hline RIGHT & 22 & $44 \%$ \\
\hline LEFT & 18 & $36 \%$ \\
\hline BILATERAL & 10 & $20 \%$ \\
\hline
\end{tabular}

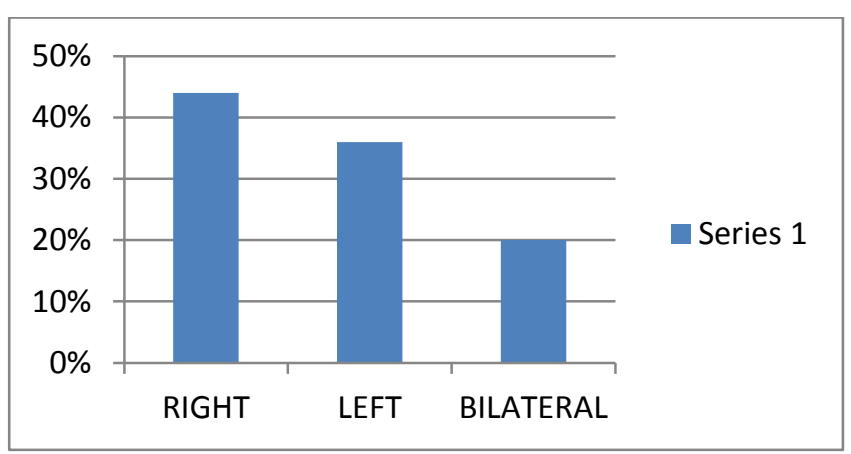

Chart No 3: Side of Injury

\section{4) BMI}

Table no: 5: Body Mass Index

\begin{tabular}{|c|c|}
\hline BMI Distribution & Number of Patients \\
\hline Underweight $(\leq 18.49)$ & 00 \\
\hline Normal (18.50 to 24.99) & 07 \\
\hline Overweight (25 to 29.99 ) & 33 \\
\hline Obese & 10 \\
\hline Total & 50 \\
\hline
\end{tabular}

\section{5) Presenting Symptoms}

Table No 6 Presenting Symptoms

\begin{tabular}{|l|c|c|}
\hline PRESENTING SYMPTOMS & FREQUENCY & PERCENTAGE \\
\hline PAIN & 50 & $100 \%$ \\
\hline SWELLIING & 35 & $70 \%$ \\
\hline BONY CREPITUS & 15 & $30 \%$ \\
\hline JOINT EFFUSION & 20 & $40 \%$ \\
\hline RESTRICTED MOBILITY & 45 & $90 \%$ \\
\hline
\end{tabular}




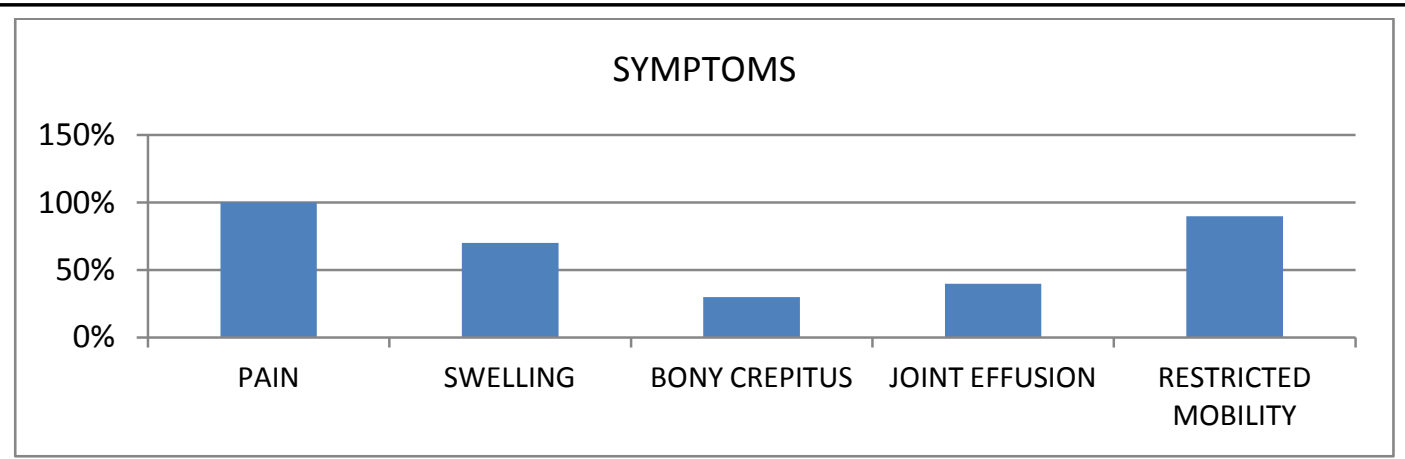

Chart No 4: Symptoms

6) Kellegren-Lawrence Radiological Grading Wise Distribution of 50 Cases

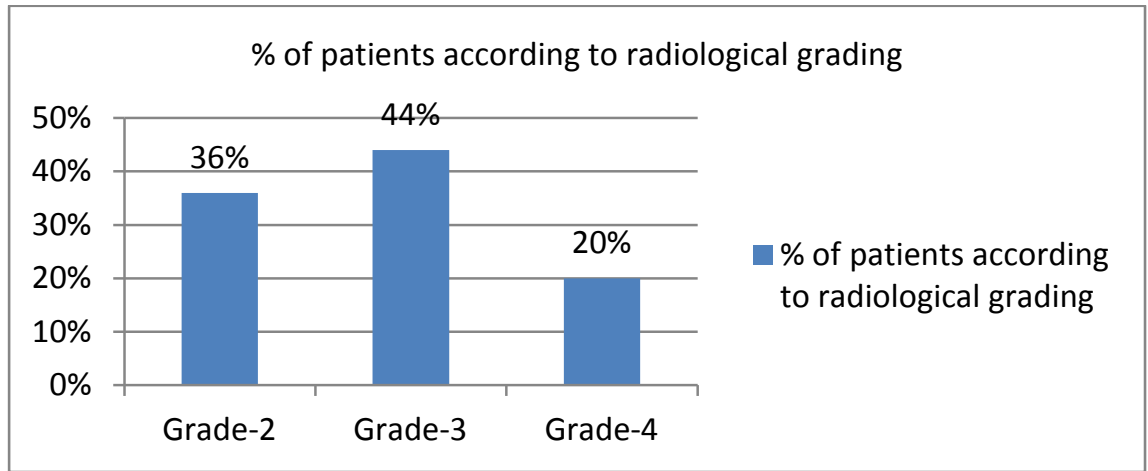

Graph 5: Radiological grading wise distribution

7) Narrowing of Joint Space on X-Ray

Table no: 7: Patients with narrowing of joint space

\begin{tabular}{|l|c|}
\hline GRADE & $\begin{array}{c}\text { NARROWING OF JOINT SPACE } \\
\text { (\% OF PATIENTS) }\end{array}$ \\
\hline 2 & $17 \%$ \\
\hline 3 & $46 \%$ \\
\hline 4 & $90 \%$ \\
\hline
\end{tabular}

8) Pre Operative- Pain Severity Score (PSS)

Table no 8: PSS was compared with previous follow up score.

\begin{tabular}{|lrrr|}
\hline Grade & 6 weeks & 3 months & 6 months \\
\hline 2 & $0 \%$ & $10.52 \%$ & $21.05 \%$ \\
\hline 3 & $0 \%$ & $26.08 \%$ & $82.60 \%$ \\
\hline 4 & $0 \%$ & $36.36 \%$ & $100 \%$ \\
\hline
\end{tabular}

9) Post Op Infection

- None of patient develops post operative infection.

10) Percentage of Patients Improved Compared to Pre - Operative PSS.

Table no:9: shows percentage of patients improved compared to pre - operative pss

\begin{tabular}{|l|c|}
\hline Grade & Improvement \\
\hline 2 & $61.11 \%$ \\
\hline 3 & $31.81 \%$ \\
\hline 4 & $0 \%$ \\
\hline
\end{tabular}




\section{Discussion}

Degenerative arthritis is the most frequent disorder in elderly patients. Knee osteoarthritis more likely to result in disability than OA of any other joint. The symptoms of OA of the knee are due to the effects of loose fragments of the articular cartilage, debris, denuding of subchondral bone, degenerative tears of menisci, loose bodies, osteophytes, synovitis, joint effusion and limited motion caused by contractors, pain and malalignment.

There are many treatment options available for the management of OA of the knee joint. Analgesics, physical and occupational therapy, arthroscopic joint debridement, joint lavage and joint replacement have all been advocated as management techniques.

Arthroscopy has been used for the management of patients with OA with varying degree, the varieties of techniques and the different methods of assessment that have been used to make a comparison of studies difficult. In order to avoid unnecessary failure rate from an indiscriminate use of arthroscopy in an OA patient. The orthopaedic surgeon must attempt to identify accurately those subsets of patients who may benefit from such surgical procedure.

Debridement procedures excise damaged portions of articular cartilage, synovial membrane or ligaments found within the joint. The removal of tissue debris during the debridement procedure improves symptoms by reducing the source of irritation of synovial tissue . $^{3}$.

Knee arthroscopy has historically been a common treatment for knee osteoarthritis. Knee osteoarthritis is a common condition affecting more than $10 \%$ of the population over 60 years old . Knee arthroscopy has been a common tool in the treatment of knee OA. However a well publicised study of Mosley et all combined with a Cochrane review of literature up to 2006 indicates that arthroscopy should not be used in knee arthritis.
In present study grade -3 constituted maximum (44\%) which is not comparable with study of Roy et al. ${ }^{4}$ where grade- 2 was observed to be maximum (53\%). But this difference may be accidental finding. Mean pain severity score in over weight patient was 19.61 and in normal weight patients was 41.29 , is showing more pain in over weight patients than normal weight patients.

Overall $18(36 \%)$ out of total 50 cases studied showed improvement after 6 months. Majority of patients improved were grade $2(61.11 \%)$ but none of the grade 4 patients showed improvement after 6 months. This is because less severe grade 2 patients have mild degenerative changes and less inflammatory reaction, whereas more severe grade 4 patients have irreversible degenerative changes and distorted mechanical axis, hence do not show improvement at all.

\section{Conclusion}

The role of arthroscopic debridement does not shows any improvement in the ongoing pathological process; it is only provides symptomatic improvement in patients of low grade osteoarthritis where it provides pain relief. Conversely, in patient with sever osteoarthritis there is very limited role of arthroscopy.

\section{References}

1. Kellgren JH, Lawrence JS. Osteo-arthrosis and disk degeneration in an urban population. Ann Rheum Dis. 1958;17(4):388-97.

2. Noyes FR, Stabler CL. A system for grading articular cartilage lesions at arthroscopy. Am J Sports Med. 1989;17(4):505-13.

3. Hunt SA, Jazrawi LM, Sherman $\mathrm{OH}$. Arthroscopic management of osteoarthritis of the knee. J Am Acad Orthop Surg. 2002;10(5):356-363. pubmed

4. Aaron RK, Skolnick AH, Reinert SE, Ciombor DM. Arthroscopic debridement for osteoarthritis of the knee. J Bone Joint Surg Am. 2006;88(5):936-43. 